\title{
Effect of cimetidine and sodium bicarbonate on pancreatic replacement therapy in cystic fibrosis
}

\author{
P R DURIE, L BELL, W LINTON, M L COREY, AND G G FORSTNER* \\ From the Kinsmen Cystic Fibrosis Research Center, and Division of Gastroenterology, \\ Department of Paediatrics, The Hospital for Sick Children, and University of Toronto, Canada
}

SUMMARY Fifteen patients with cystic fibrosis and pancreatic insufficiency were studied during four randomised seven day treatment periods in which they received only pancreatic supplement (Pancrelipase, 27 capsules per day) or supplement plus cimetidine $(20 \mathrm{mg} / \mathrm{kg}$ body weight $/ 24 \mathrm{~h})$ or sodium bicarbonate $\left(15 \mathrm{~g} / \mathrm{m}^{2} / 24 \mathrm{~h}\right)$ alone or in combination. Dietary intake was not fixed but was restricted to foods of known fat and nitrogen content from which daily intakes could be computed. Faecal fat and nitrogen were calculated as $\mathrm{g} / 24 \mathrm{~h}$ and percentage of intake. Addition of either cimetidine or bicarbonate resulted in significant improvement in fat and nitrogen excretion, which was not greater with the combination of both drugs. Cimetidine and sodium bicarbonate in these doses are therefore sufficient to produce maximal improvement in digestive activity of pancreatic supplements. Fat excretion per gram of intake fell with cimetidine and bicarbonate from 12 times the normal level, to normal, in patients consuming less than $120 \mathrm{~g}$ fat daily. Above this intake the dose of pancreatic supplement appeared to be inadequate. Faecal nitrogen excretion increased with nitrogen intake in all four periods, but, in contrast with fat excretion, the response to cimetidine and bicarbonate was not affected by the level of intake. Dietary intake appears to be a significant factor in determining the faecal output of fat and nitrogen in patients with pancreatic insufficiency and should be considered when determining the optimum amount of pancreatic supplementation.

Cystic fibrosis (CF) is a disease in which 80 or $90 \%$ of affected patients have total, or near total, loss of pancreatic function ${ }^{12}$ associated with malabsorption of protein and fat. As with other causes of pancreatic insufficiency (PI) these patients have been treated for many years with supplemental pancreatic enzymes, primarily of porcine origin. ${ }^{3}$ Symptomatic improvement is achieved in most cases but steatorrhoea persists, often in the range of 20 to $50 \%$ of ingested fat. ${ }^{4-7}$

The failure to correct steatorrhoea in these patients is principally explained by acid-peptic destruction of exogenous pancreatic enzymes in the stomach, resulting in inadequate delivery to the duodenum. ${ }^{89}$ Various authors have reported improvement of fat and protein absorption with agents which inhibit gastric secretion such as cimetidine ${ }^{410}$ and metiamide $^{9}$ by agents which neutralise gastric acidity, principally sodium bicarbonate ${ }^{11-14}$ and by acid resistant enteric coating of administered en-

*Address for correspondence: Dr G G Forstner, The Hospital for Sick Children, 555 University Avenue, Toronto, Ontario, Canada, M5G 1 X8.

Received for publication 18 April 1980 zymes. ${ }^{1516}$ The superiority of a given approach has not been established, however. Only one study has attempted to compare the use of more than one of these modifications in the same group of patients.10 In no study has there been an effort to determine whether the additional agent was delivered in a concentration which would produce maximum results.

The present study was designed to compare the use of cimetidine and sodium bicarbonate as adjuncts to pancreatic enzyme therapy in a restricted population of adolescent patients with cystic fibrosis and steatorrhoea and to test for the possibility of suboptimal dosing of each agent. As patients were permitted variable fat and protein intakes according to their habitual diet we have also been able to explore the role of dietary load on the response.

\section{Methods}

Twenty-one patients with cystic fibrosis, aged 10 to 17 years, who attended the cystic fibrosis clinic at The Hospital for Sick Children, Toronto, entered 
the study. The diagnosis had been confirmed previously by a raised sweat chloride determination $(>60 \mathrm{mmol})$. All patients had malabsorption by history and were receiving pancreatic enzyme replacement therapy. Patients were selected from a restricted geographical area in proximity to the hospital, on the basis of an assessment by clinical personnel of their ability to perform a clinical study accurately at home. Individuals with normal pancreatic function, cardiac disorders, hepatobiliary disease, diabetes, or severe pulmonary symptoms were excluded. Informed consent was obtained from each patient and his/her parents or legal guardian.

Of 21 patients who entered the study, two withdrew voluntarily after three days. Three patients were withdrawn on evidence of poor drug and diet compliance, plus inadequate stool collections, and one patient was withdrawn because of a possible complication from cimetidine, consisting of transient left-sided weakness and paraesthesiae. Fifteen patients successfully completed the study and are reported upon below.

Throughout the four week study, each patient was maintained on 26 pancrelipase capsules (Cotazym, Organon) per day, six capsules with meals and three per snack. All capsules were from a single batch obtained from the manufacturer. The study was subdivided into four sequential treatment periods designed to compare the effect of cimetidine and/or sodium bicarbonate on fat and nitrogen absorption as follows: (1) pancrelipase alone; (2) pancrelipase and sodium bicarbonate (supplied as $\mathbf{3 0 0} \mathrm{mg}$ tablets. National Drug House, Toronto, Canada), (3) pancrelipase and cimetidine (supplied as $\mathbf{2 0 0} \mathrm{mg}$ and $\mathbf{3 0 0} \mathrm{mg}$ tablets, by Smith, Kline \& French, Canada Ltd), (4) pancrelipase with sodium bicarbonate and cimetidine. Sodium bicarbonate was given in a dose of $15 \mathrm{~g} / \mathrm{m}^{2} / 24 \mathrm{~h}$ to a maximum of $16.2 \mathrm{~g}$, divided in a ratio of 3 to 1 for meals and snacks respectively. Cimetidine was given in four equally divided doses, one hour after food, and at bedtime in a total daily dose of $20 \mathrm{mg} / \mathrm{kg}$ to a maximum of $1200 \mathrm{mg} / 24 \mathrm{~h}$. Each patient was randomly assigned a different sequence of treatment periods. Each period consisted of three days of equilibration followed by four days of stool collection.

A registered nurse, experienced in clinical investigation and trained to perform venepuncture, was employed to coordinate the study. She visited each family home at least twice before starting the study and the day after each treatment period. At the start of the study she provided instruction for the completion of accurate food records, the collection and storage of stool, and the administration of experimental drugs. During the study the nurse, or one of us (PRD), was available to answer questions by telephone at all times. More frequent home visits were provided when necessary. No more than five patients took part in the study at one time.

A research nutritionist (LB), experienced in clinical investigation, planned and supervised the dietary aspects of the study. During the initial home visit the study nurse, with the direction of the research nutritionist, provided instructions for meal planning so that food records would be accurate. Patients were asked to consume the types and quantities of foods normally eaten. The amount of each food served was weighed using a dietary scale (Quality Platform Scale, no. 1449, Hanson Scale Co, $500 \mathrm{~g}$ max.) and recorded on a daily record sheet after subtracting the amount remaining on the plate. Specific instructions contributed to the accuracy of these records. Combination foods were described in detail-for example, sandwich-Toastmaster white bread $50 \mathrm{~g}$, Maple Leaf butter $10 \mathrm{~g}$, Kraft cheeze-whiz $15 \mathrm{~g}$, lettuce $7 \mathrm{~g}$. Patients recorded the amount of fat used in cooking and noted the mode of cooking - for example, broiled chops, roast chicken. Foods eaten away from home were preweighed. Detailed recipes were obtained for all home-prepared dishes such as casseroles, stews, and puddings. Brand names of all foods were recorded. Each food item consumed was coded by the nurse and the daily intake of calories, protein, and fat calculated using a computerised nutrient calculation system developed at the Hospital for Sick Children. ${ }^{17}$ These calculations were derived from a nutrient data bank which included brand name foods commonly used in Canada.

Investigational drugs including pancrelipase, cimetidine, and sodium bicarbonate were issued at the beginning of each seven day balance period in individual containers with clearly marked prescribing information attached. All other drugs, including antibiotics or vitamin supplements, were taken as normally prescribed.

Stool collections were stored in preweighed, sealable gallon paint cans and maintained at $4^{\circ} \mathrm{C}$ in styrofoam picnic coolers with ice cubes or ice packs. A stool sheet was used to record the nature and frequency of bowel motions.

At the end of each study period the study nurse obtained the stool collection, stool sheets, seven-day food records with recipe sheets and drug containers with any remaining drugs. At the same time the stool can, record sheets, and drugs to be used in the ensuing balance period were issued. The nature of any unusual drug reactions was noted. Any complications, difficulties, or deviations from the protocol were noted and a remedy suggested. Stool collections were immediately weighed and stored at $-20^{\circ} \mathrm{C}$ until analysed. 
Clinical laboratory tests were performed before and at completion of the study including urinalysis, complete blood count with differential, reticulocyte and platelet counts, serum determinations of total and direct bilirubin, glutamic oxaloacetic transaminase, alkaline phosphatase, creatinine, uric acid, sodium, potassium, chloride, and blood urea nitrogen. Additional, weekly laboratory tests included urinalysis, complete blood count, differential, reticulocyte and platelet counts with serum determinations of creatinine, sodium, potassium chloride, and blood urea nitrogen.

Individual stool collections were analysed in duplicate for fat $^{18}$ and nitrogen ${ }^{19}$ using previously described methods. Stool fat and nitrogen were expressed in grams and percentage of intake excreted per day.

To ensure that the measurements of stool fat and nitrogen were not biased by irregularities of the dietary intakes the components of variance of the daily intakes of calories, fat, and protein were studied using the analysis of variance for crossclassifications (randomised blocks) with subsampling. ${ }^{20}$ Faecal outputs of fat and protein were compared by analysis of variance for randomised blocks and Student's $t$ test for paired observations. Computations were done with the Statistical Analysis System. ${ }^{21}$

\section{Results}

NUTRITIONAL INTAKES :

Subjects consumed a mean daily intake of $2747 \pm 13 \cdot 3$ $\mathrm{kcal}, 116 \pm 39.9 \mathrm{~g}$ fat, and $111.0 \pm 39.5 \mathrm{~g}( \pm \mathrm{SD})$ protein during the study. The mean daily intakes were not significantly different during the four treatment periods. Analysis of variance of daily intakes of protein and fat showed that $99 \%$ of the variance was explained by individual differences and day to day variation. The variance component due to treatment periods was less than $1 \%$. A slight, systematic tendency for caloric intake to decrease during the study was noted, but, because of random assignment of treatment orders, this tendency had no effect on the means of the four treatment periods. Nutrient intakes in our patients were found to be the same as those calculated by a 24 hour recall method for normal children living in Ontario and reported in Food Consumption and Patterns Report, Nutrition Canada. ${ }^{22}$

Daily intakes of fat and protein varied approximately three-fold between patients. There was an excellent correlation between both body weight and fat intake $(r=0.73, \mathrm{P}<0.01)$ and body weight and protein intake $(r=0.78, \mathrm{P}<0.01)$. Fat and protein intakes were correlated equally strongly with height and age indicating that the diets reflected the growth and maturity of the adolescent patients in the study. When fat and protein intake was expressed per $\mathrm{kg}$ body weight correlations with age and height disappeared.

\section{EFFECT OF VARIABLE INTAKE ON FAT AND NITROGEN EXCRETION, PERIOD 1: \\ (PANCRELIPASE WITHOUT SUPPLEMENT)}

Faecal losses of fat and nitrogen were strongly correlated with fat and nitrogen intake (Fig. 1). The regression equation relating faecal fat $(y=g$ fat output $/ 24 \mathrm{~h})$ and dietary fat $(\mathrm{x}=\mathrm{g}$ fat intake $/ 24 \mathrm{~h})$ was $\mathrm{y}=0.262 \mathrm{x}+1.04(r=0.66, \mathrm{P}<0.01)$. The slope
Fig. 1 The relationship between fat intake and faecal fat $(A)$, and nitrogen intake and faecal nitrogen (B). Individual results are shown for the 15 study subjects during period 1. The regression lines are for the 15 cystic fibrosis patients during period 1 ( - _ ) , 10 patients studied by Cox et al.4 (_- - ), normal fat excretion ( $N$ ) from Wollaeger et al., ${ }^{24}$ and normal nitrogen excretion ( $N$ ) arbitrarily expressed as $10 \%$ of intake.

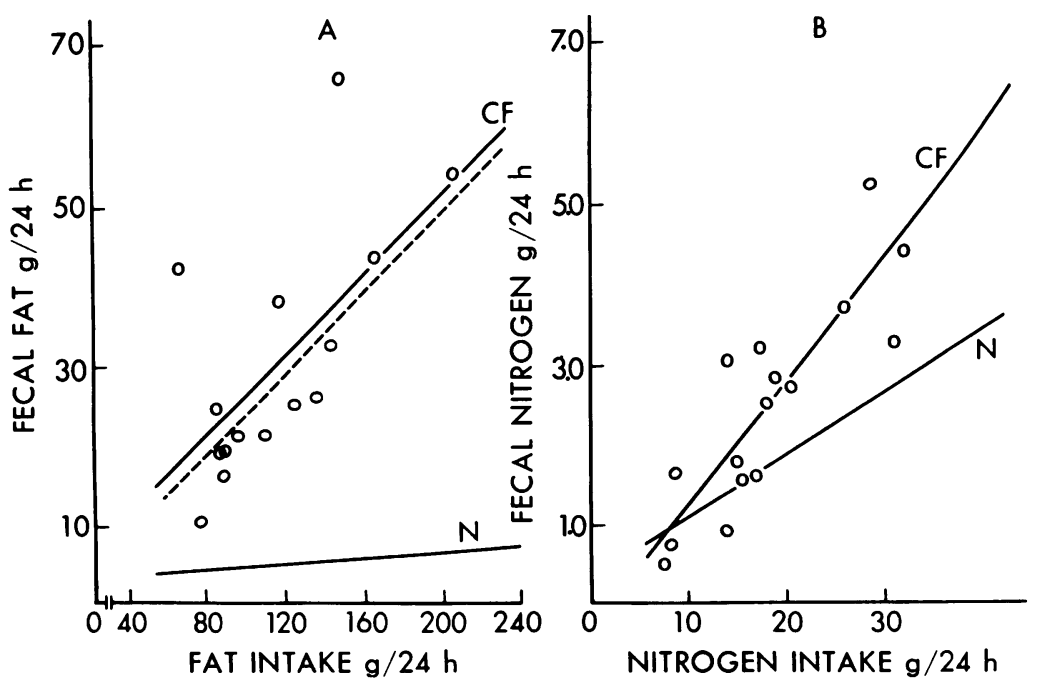


Table Stool fat and nitrogen excretion in four treatment periods

\begin{tabular}{|c|c|c|c|c|c|}
\hline \multirow[t]{2}{*}{ Treatment period } & \multicolumn{2}{|l|}{ Faecal fat } & \multicolumn{2}{|c|}{ Faecal nitrogen } & \multirow{2}{*}{$\begin{array}{l}\text { Faecal weight } \\
\text { (g/day) }\end{array}$} \\
\hline & $g / 24 h$ & $\%$ of intake & $g / 24 h$ & $\%$ of intake & \\
\hline $\begin{array}{l}1 \text { Pancrelipase alone } \\
2 \text { Pancrelipase + bicarbonate } \\
3 \text { Pancrelipase + cimetidine } \\
4 \text { Pancrelipase + bicarbonate + } \\
\text { cimetidine }\end{array}$ & $\begin{array}{l}31 \cdot 3 \pm 15 \cdot 5 \\
19 \cdot 3 \pm 12 \cdot 7 \ddagger \\
20 \cdot 3 \pm 12 \cdot 6 \dagger \\
18 \cdot 0 \pm 10 \cdot 7 \ddagger\end{array}$ & $\begin{array}{l}27 \cdot 6 \pm 13 \cdot 3 \\
16 \cdot 8 \pm 9 \cdot 9 \ddagger \\
17 \cdot 8 \pm 9 \cdot 7 \dagger \\
14 \cdot 8 \pm 5 \cdot 8 \dagger\end{array}$ & $\begin{array}{l}2 \cdot 57+1 \cdot 4 \\
1 \cdot 91 \pm 1 \cdot 31 \dagger \\
1 \cdot 91 \pm 1 \cdot 36 \dagger \\
2 \cdot 14 \pm 1 \cdot 31 \dagger\end{array}$ & $\begin{array}{l}13 \cdot 7+4 \cdot 9 \\
10 \cdot 4 \pm 6 \cdot 4 \dagger \\
10 \cdot 3 \pm 5 \cdot 6 \dagger \\
11 \cdot 4 \pm 5 \cdot 6 *\end{array}$ & $\begin{array}{l}277 \pm 145 \\
225 \pm 145 \dagger \\
224 \pm 124 \dagger \\
225 \pm 134 \dagger\end{array}$ \\
\hline
\end{tabular}

Statistical significance of results in each treatment period when compared with period 1:

$* \mathbf{P}<0.05,+\mathbf{P}<0.01$, $\mathbf{P}<0.001$.

of the regression line for fat excretion is contrasted in Fig. 1a with the regression line for normal subjects established by Wollaeger et al. (1947) $(y=0.021 x+2.34)$. The slopes for these lines are significantly different $(P<0.05)$ if one assumes a similar degree of variation in the two groups. From them it can be calculated that during almost the entire range of fat intake, the patients with cystic fibrosis excreted 12.5 times as much fat per gram of fat intake as normal subjects even while taking pancreatic supplements. Figure 1a also includes a regression line calculated from the data of Cox et al. ${ }^{4}$ (regression equation, $y=0 \cdot 26 x-2 \cdot 20$ ) who also allowed their patients variable fat intake. Even though the dose of pancreatic supplement used in their study was much smaller than we used, the slopes of the regression lines are almost identical, which suggests that the enhanced rate of fat excretion in our patients is generally typical of cystic fibrosis patients on pancreatic supplements.

The regression equation relating faecal $\mathrm{N}(\mathrm{y}=\mathrm{gN}$ output/24 h) and dietary $\mathrm{N}(\mathrm{x}=\mathrm{gN}$ intake/24 h) was $\mathrm{y}=0.189 \mathrm{x}-0.816 \quad(r=0.86, \quad \mathrm{P}<0.001) . \quad$ Nitrogen excretion in normal individuals varies slightly ${ }^{23-26}$, if at all ${ }^{27}$ with intake but normal excretion over a wide range of protein intake has not been established as precisely as it has for fat. If the commonly accepted index that nitrogen excretion should not exceed $10 \%$ of intake is used for normal subjects, it is possible to compare it with nitrogen excretion as a function of intake in our cystic fibrosis patients. The regression line for nitrogen excretion in our cystic fibrosis patients is contrasted with the $10 \%$ excretion line in Fig. 1b. The slopes for these lines were not markedly different $(0 \cdot 189 x$ and $0 \cdot 1 x)$, suggesting that our patients on pancreatic supplements were excreting approximately twice as much nitrogen per gram of nitrogen intake as one would expect for the upper limit of normal performance.

\section{EFFECT OF ADJUNCTIVE SODIUM}

BICARBONATE AND/OR CIMETIDINE

Both sodium bicarbonate and cimetidine were taken with little incident. Two patients complained of

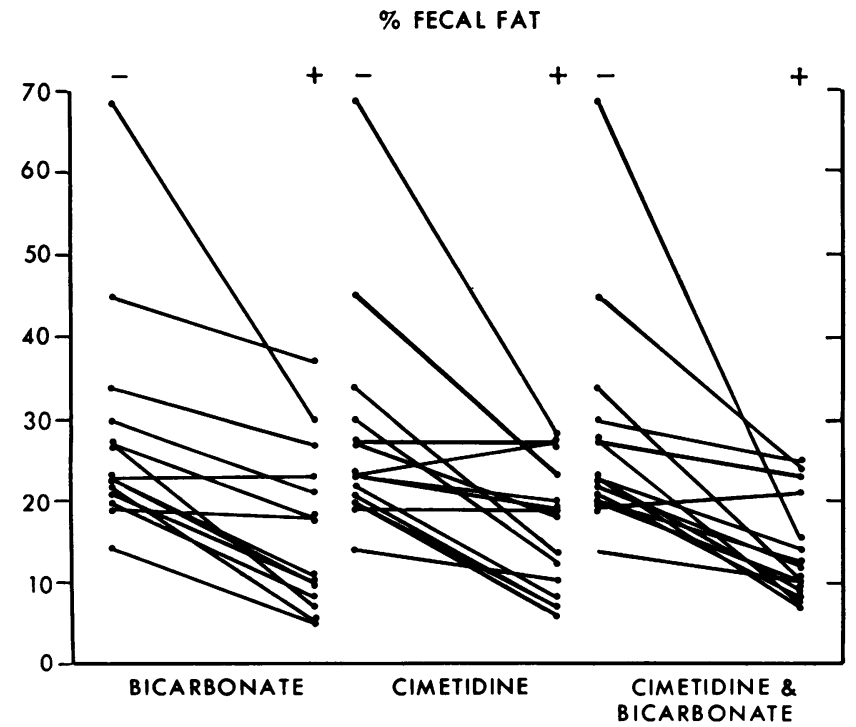

Fig. 2 Individual responses in faecal fat excretion to the addition of bicarbonate and/or cimetidine to pancreatic supplementation. In each panel the results designated (-) indicate values obtained on pancreatic supplement without additions - that is period 1-while results designated $(+)$ indicate the response. 
gaseous abdominal distention while taking bicarbonate, while one patient at first had difficulty in swallowing the tablets. One patient (see Methods section) was forced to withdraw from the study because of possible neurological complications due to cimetidine. Chemical indices were unaltered in all patients.

All three adjunctive schedules significantly improved mean fat and nitrogen absorption whether expressed as $\mathrm{g}$ per 24 hours or percentage of intake (Table). Percentage fat output fell by an average of $10.8 \%$ with added bicarbonate, $9.8 \%$ with cimetidine and $12.8 \%$ with the combination. These results were not significantly different from each other. The improvement in mean faecal nitrogen excretion with the addition of cimetidine or sodium bicarbonate was much less dramatic, $3 \cdot 3 \%, 3 \cdot 4 \%$, and $2.3 \%$, but, in each case, addition of these drugs resulted in a significant reduction in output. Again there was no evidence that a combination of the two drugs produced superior results. Although mean stool frequency was the same from treatment period to treatment period (1.3/day), adjunctive bicarbonate and/or cimetidine resulted in a significant reduction in mean daily faecal weight (Table).

Individual responses in percentage fat excretion are shown in Fig. 2. Percentage fat output was reduced in 11 patients with bicarbonate, 10 with cimetidine, and 11 with bicarbonate and cimetidine. Only one patient failed to respond to at least one of these treatments. The explanation for failure in this case was not apparent. A careful attempt to evaluate compliance indicated that the pills were taken throughout the study. Five patients with sodium

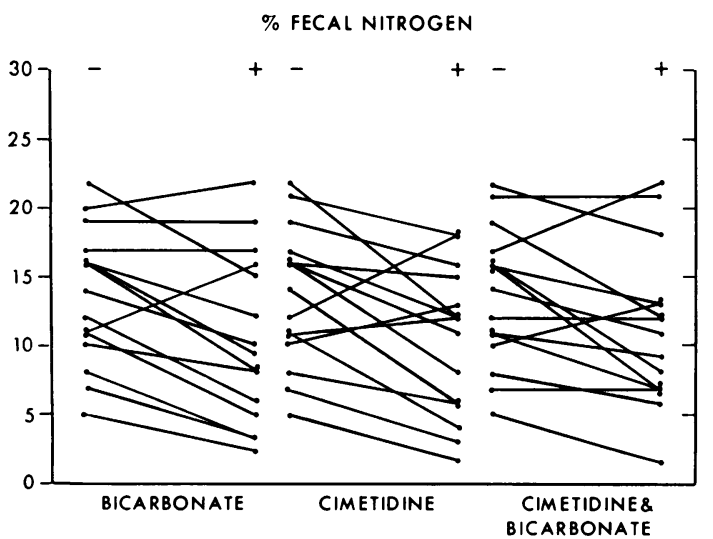

Fig. 3 Individual responses in faecal nitrogen excretion, to the addition of bicarbonate and/or cimetidine to pancreatic supplementation. In each panel the results designated (-) indicate values obtained on pancreatic supplement without additions-that is, period 1 -while results designated $(+)$ indicate the response.

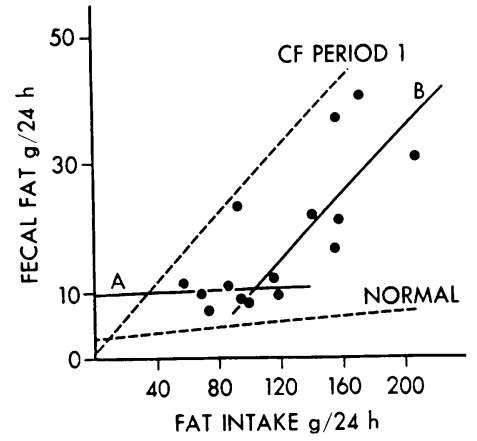

Fig. 4 Faecal fat excretion as a function of fat intake while subjects were taking cimetidine and bicarbonate in addition to pancreatic supplements - that is period 4. Individual results (○), regression lines (_-_), A for lowest nine intakes, $B$ for highest nine intakes. Dotted lines represent the regression equations for period 1, and normal subjects, as in Fig. 2.

bicarbonate, four with cimetidine, and five with bicarbonate and cimetidine reduced their percentage fat output to $10 \%$ or less of intake. However, only three results (two on bicarbonate, and one on cimetidine) fell below $7 \%$ of intake, which is probably a more accurate upper limit for normal fat excretion. ${ }^{24}$ In general, the lowest percentage outputs on the adjunctive schemes were achieved in those patients with the least degree of steatorrhoea on pancrelipase alone. Perhaps more importantly the two patients with fat excretion in excess of $40 \%$ of intake on pancrelipase alone achieved remarkable percentage improvements in fat excretion of $52 \%$ and $22 \%$ respectively in their best periods.

Individual improvement in percentage faecal nitrogen excretion was much less dramatic than that for fat and exhibited more variability from treatment period to treatment period (Fig. 3). On the other hand percentage nitrogen excretion was improved at least marginally in a similar number of patients, 12 on bicarbonate, 12 on cimetidine, and 10 on the combination. The number of patients with nitrogen excretion less than $10 \%$ of intake rose from three in period 1 to nine on bicarbonate, seven on cimetidine, and six on the combination.

INFLUENCE OF DIETARY INTAKE ON EXCRETION DURING ADJUNCT THERAPY

Figure 4 compares the regression lines for fat excretion calculated from the results in period 1 , and the data of Wollaeger et al. ${ }^{24}$ (see Fig. 1), with results obtained on the combination of cimetidine and bicarbonate. Whereas inspection of the data for period 1 while taking only pancrelipase failed to disclose a level of intake beyond which the output of 
fat was suddenly altered, this was not true of the data for cimetidine and bicarbonate. With the exception of one patient, fat excretion per gram of intake paralleled normal excretion up to an intake of approximately $120 \mathrm{~g}$, then rose. As the point of diversion appeared to be in the range of 100 to $120 \mathrm{~g}$ of fat intake, regression equations were determined separately for the lowest nine and the highest nine intakes, so as to overlap this zone. The equation for the lowest nine intakes was $y=0.019 x+9.69$ and for the highest nine intakes $y=0 \cdot 267 x-16.98$. The regression lines calculated for these equations are shown in Fig. 4. For the lower intakes the slope is almost identical with the slope for normal individuals, although it crosses the y axis at a higher level of fat excretion. The slope for the higher

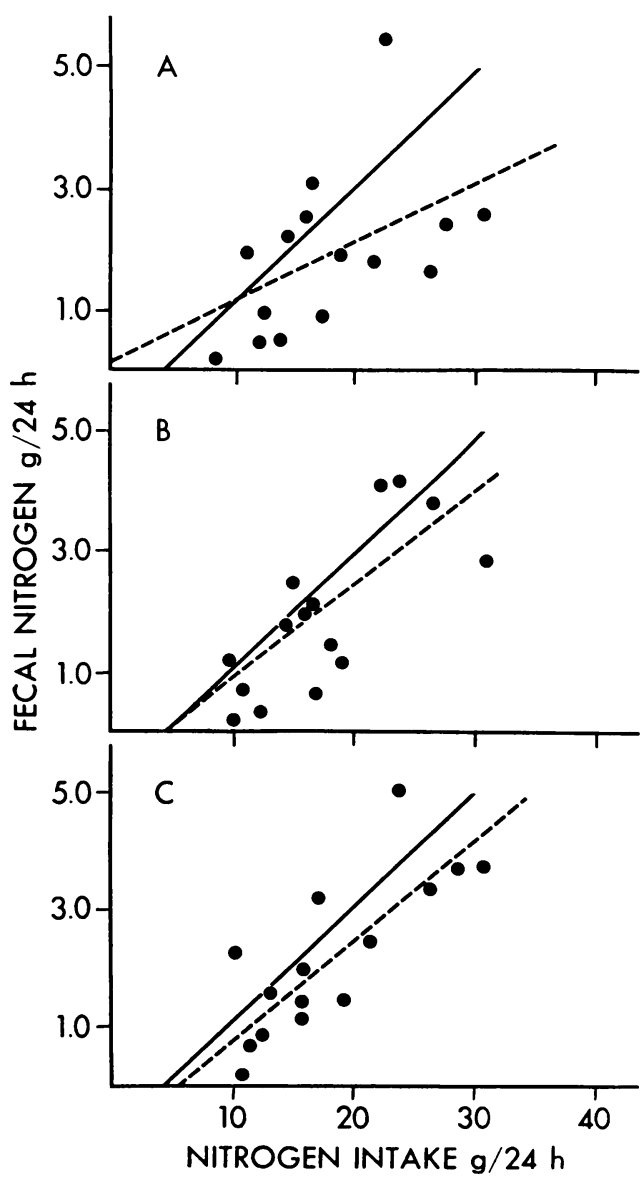

Fig. 5 Faecal nitrogen excretion as a function of nitrogen intake for $A$, period $2 ; B$, period 3 , and $C$, period 4. Solid circles represent individual results for each period. Regression lines for the results in each period ( - - ) are contrasted with the regression line for period 1 ( intakes is identical with the slope for data in period 1. Thus cimetidine and bicarbonate appear to have reduced fat excretion to normal values at intakes of less than $120 \mathrm{~g}$ per day; beyond this point the rise in excretion per gram of intake was similar to that found without adjuncts.

Nitrogen output is plotted as a function of nitrogen intake for the three adjunct treatment periods in Fig. 5. In each case the regression line calculated for the period is compared with the regression line for nitrogen excretion in period 1 . Unlike fat excretion there was no evidence of a significant break-point in the individual results beyond which excretion rose dramatically with intake. Results obtained with bicarbonate were interesting in that the principal cause of the diminished slope of the regression line was a relatively greater fall in output in the three patients with the highest intake. This improvement was not seen when these patients were placed on cimetidine as well as bicarbonate. As expected from the mean data, the differences in the regression equations were minor and not statistically significant.

\section{Discussion}

Our results demonstrate that both mean fat and mean nitrogen absorption in patients with cystic fibrosis and pancreatic insufficiency can be significantly improved by the addition to pancreatic supplements of either cimetidine or antacid. Similar findings for cimetidine have been reported previously by Regan et al. ${ }^{10}$ in patients with chronic pancreatitis, and by Cox et al. ${ }^{4}$ in patients with cystic fibrosis. Regan et al. ${ }^{10}$ failed to obtain comparable results, however, with either sodium bicarbonate or Maalox. The difference between their study and ours is almost certainly accounted for by the quantity and timing of the sodium bicarbonate dose. Regan et al. ${ }^{10}$ used a dose of $2.5 \mathrm{~g}$ sodium bicarbonate, 30 minutes after each meal, whereas our patients received up to $3.6 \mathrm{~g}$ sodium bicarbonate evenly distributed in $300 \mathrm{mg}$ tablets throughout the meal with additional sodium bicarbonate with snacks. A comparable dose had previously been shown to be effective in alleviating steatorrhoea in patients with cystic fibrosis by Weber et al..$^{14}$ Our results suggest that the doses of cimetidine and sodium bicarbonate used in these studies were nearly optimal in terms of achieving their maximum effectiveness, as the administration of both drugs together failed to improve mean fat or nitrogen absorption significantly.

Interestingly, in the 31 patients comprising the three cimetidine studies including our own, normalisation of faecal fat to less than $7 \%$ of intake was achieved in only three cases. All three studies used a 
dose of cimetidine which has been shown to be optimally effective in maintaining gastric $\mathrm{pH}$ above 4.9.10 Cox et $a l .^{4}$ analysed plasma cimetidine levels and found that these were in the normal therapeutic range in a majority of patients, including some who failed entirely to respond. In our study the simultaneous administration of cimetidine and sodium bicarbonate failed to increase the number of normal fat excretion values. These results appear to rule out the possibility that patient compliance, inadequate dosage, or inadequate acid neutralisation can account for the failure to normalise fat excretion.

The results presented in Fig. 4 suggest that an important variable in studies which permit unrestricted fat intake during balance periods may be the relationship between the amount of pancreatic supplement administered and the total fat load. When patients received only pancrelipase, fat excretion appeared to be a linear function of fat intake, increasing at a rate of approximately $0.25 \mathrm{~g}$ of fat excreted for every incremental gram of intake. This rate of excretion per gram of intake is approximately 12.5 times greater than that seen in normal individuals. ${ }^{24}$ The slope of our regression line was surprisingly similar to that which can be calculated from the data of Cox et al., ${ }^{4}$ in which a much smaller dose of Cotazym was administered, suggesting that very little benefit was achieved in our patients by increasing the dose of pancrelipase per se. From the intersection point with the data of Wollaeger et $a .^{24}$ for normal adults these results would suggest that the maximal digestive capacity of the enzyme supplements was overwhelmed at an extremely low level of fat intake, somewhere between 0 and $20 \mathrm{~g} / 24 \mathrm{~h}$. In contrast, in patients on the combined sodium bicarbonate and cimetidine treatment who were taking less than $120 \mathrm{~g}$ fat per day, fat excretion increased with increasing intake at a rate which was much more typical of normal subjects. The rate of fat excretion in patients taking larger amounts of fat increased much more rapidly with a slope similar to that of the patients on pancrelipase alone. Our data suggest therefore that patients with fat consumption over $120 \mathrm{~g}$ per day may not have received sufficient pancrelipase to promote optimum digestion even in the presence of optimum amounts of bicarbonate and cimetidine. It is possible that patients in this higher range of fat intake may benefit from larger doses of pancreatic enzyme supplementation. Interestingly, the range of values achieved by Regan et al..$^{10}$ with cimetidine plus viokase using a fixed $100 \mathrm{~g}$ balance (6 to $15 \%$ ) was smaller than either of the two studies in patients with cystic fibrosis, both of which allowed variable fat intake to levels considerably in excess of $100 \mathrm{~g}$. These results have important implications for supplementation of patients on unrestricted diets, as it is quite possible that a supplement which is proved to be adequate on an arbitrary fixed balance may be inadequate on the diet actually taken by the patient.

Variations in intake do not account for the failure of some patients to achieve a significant response with any regimen. As our study was performed at home, it is possible that compliance may have been a factor in some of the latter cases, in spite of surveillance, but similar failures have been noted by others ${ }^{4}$ in closely supervised conditions. Patients with cystic fibrosis have been shown to have a diminished bile salt pool and increased excretion of faecal bile acids, but these abnormalities appear to be minimal once pancreatic supplements and antacids are introduced. ${ }^{28}{ }^{29}$ Diminished absorption of fatty acids has been reported in cystic fibrosis, however, ${ }^{60}$ and mucosal abnormalities have also been described, ${ }^{41}$ which may limit fat absorption. These factors may account for the fact that the regression line for lower intakes shown in Fig. 4 has a y intercept of $9.69 \mathrm{~g}$, considerably greater than the $\mathrm{y}$ intercept of $2.96 \mathrm{~g}$ for normal individuals. ${ }^{24}$ If one can assume that the efficacy of pancreatic supplementation was totally restored in these patients by the addition of bicarbonate and cimetidine, the higher level of fat excretion at these intakes might be explained by absorptive rather than digestive factors.

The interpretation of the impact of bicarbonate and cimetidine on $\mathrm{N}$ excretion is hampered by a comparative absence of data relating faecal $\mathbf{N}$ to $\mathrm{N}$ intake in normal individuals particularly at $\mathrm{N}$ intakes in excess of $20 \mathrm{~g} / 24 \mathrm{~h}$. Reifenstein et al. ${ }^{27}$ studied faecal nitrogen excretion in normal subjects over a wide range of nitrogen intake from 2.9 to $38.65 \mathrm{~g} /$ day and found that nitrogen excretion remained constant. Wollaeger et al. ${ }^{24}$, however, reported a range of 0.6 to $1.9 \mathrm{~g}$ faecal nitrogen per day (mean $1.2 \mathrm{~g}$ per day) in adults on a diet containing $15.6 \mathrm{~g}$ nitrogen, and a slightly higher range of 0.8 to $2.5 \mathrm{~g}$ per day (mean $1.7 \mathrm{~g}$ per day) on a diet containing $18.8 \mathrm{~g}$ per day. More recently Cheng et $a .^{26}$ studied young adults on three different nitrogen intakes of $0.4,0.8$, and $1.6 \mathrm{~g}$ protein per $\mathrm{kg}$ per day and found that faecal nitrogen was linearly correlated with intake. Young et al ${ }^{25}$ found that faecal nitrogen tended to increase with egg protein intake. Thus, although faecal nitrogen losses are commonly stated to be independent of intake, some studies indicate that losses may, in fact, increase.

On Fig. 1 we compared period 1 output on a variable nitrogen intake with an arbitrary slope based on a normal value for nitrogen excretion of $10 \%$. This corresponds to a value of $1 \mathrm{SD}$ above 
the mean based on the results of Lapey et $a .^{32}$ (mean nitrogen excretion $=7 \cdot 1 \pm 2 \cdot 9 \%$ ) and is a value commonly used in clinical practise. ${ }^{27}$ Nevertheless Reifenstein et al. ${ }^{27}$ have shown that this value may overstate the normal range at higher nitrogen intakes.

For the moment it seems safe to conclude that in cystic fibrosis patients with pancreatic insufficiency, even with maximum preservation of supplement activity, nitrogen excretion rises with nitrogen intake, whereas this may or may not be the case in normal subjects. Nitrogen excretion per gram of intake in the cystic fibrosis patients exceeded that for normal subjects approximately two-fold if normal excretion is taken as $10 \%$ of intake. The difference between nitrogen excretion rates in cystic fibrosis and normal subjects is therefore much less dramatic than in the case of fat.

Although our data indicate that nitrogen excretion is generally improved by the addition of cimetidine and bicarbonate, the improvement was marginal and independent of intake. The persistence of high nitrogen excretion during periods in which digestive function was, to judge from fat output, much improved, is surprising. It is unlikely that proteases were protected less well than lipase, as the effect of acid inhibition has been shown to preserve both to the same extent. ${ }^{9}$

Azotorrhoea was also less severe than steatorrhoea before adjunct therapy and one would expect therefore that moderate preservation of enzyme activity would have a decisive effect. Alternatively, it is possible that nitrogen excretion is not closely tied to digestive activity in these patients. Gibson et al $^{33}$ pointed out that there is a significant increase in the amount of faecal nitrogen excreted with increasing dietary protein in subjects without a functioning colon. They concluded that the colon plays a significant part in nitrogen absorption which apparently obliterates much of the effect of diet. It is possible therefore that the higher rates of nitrogen excretion in our cystic fibrosis patients reflect altered colonic function such as an increase in colonic transit, or a change in bacterial flora, especially as the latter may be affected by antibiotics. If so, one would expect to find relatively little improvement through increasing the efficiency of pancreatic supplements, as indeed seems to be the case.

We would like to thank Smith Kline \& French, Canada for their generous financial support for this project, and the Canadian Cystic Fibrosis Foundation for providing a fellowship for Dr P R Durie. We would also like to thank Dr D Crozier and Dr $\mathrm{H}$ Levison for their help in assisting us to study patients under their personal care.

\section{References}

${ }^{1}$ Di Sant'Agnese PA. Fibrocystic disease of the pancreas with normal or partial pancreatic function. Pediatrics 1955; 15: 683-96.

'Shwachman H, Dooley RR, Guilmette F, Patterson PR, Weil C, Leubner H. Cystic fibrosis of the pancreas with varying degrees of pancreatic insufficiency. $A m J$ Dis Child 1956; 92: 347-68.

${ }^{3}$ Graham DY. Enzyme replacement therapy of exocrine pancreatic insufficiency in man. N Engl J Med 1977; 296: 1314-17.

${ }^{4}$ Cox KL, Isenberg JN, Osher AB, Dooley RR. The effect of cimetidine on maldigestion in cystic fibrosis. J Pediatr 1979; 94: 488-92.

${ }^{5}$ Goodchild MC, Segaro E, Brown GA, Cruchley PM, Jukes HR, Anderson CM. Comparative trial of pancrex $\mathrm{V}$ forte and nutrizym in treatment of malabsorption in cystic fibrosis. $\mathrm{Br} \mathrm{Med} J$ 1974; 3: 712-4.

${ }^{6}$ Matthews LW, Spector S. Break-through in cystic fibrosis. Pediatrics 1961; 27 : 351-3.

${ }^{7}$ Ross CAC. Fat absorption studies in the diagnosis and treatment of pancreatic fibrosis. Arch Dis Child 1955; 30: 316-321.

${ }^{8}$ DiMagno EP, Malagelada JR, Go VLW, Moertel CG. Fate of orally ingested enzymes in pancreatic insufficiency. N Engl J Med 1977; 296: 1318-22.

${ }^{9}$ Saunders JHB, Wormsley KG. Pancreatic extracts in the treatment of pancreatic exocrine insufficiency. Gut 1975; 16: 157-62.

${ }^{10}$ Regan PT, Malagelada JR, DiMagno EP, Glanzman SL, Go VLW. Comparative effects of antacids, cimetidine and enteric coating or the therapeutic response to oral enzymes in severe pancreatic insufficiency. N Engl J Med 1977; 297: 854-8.

${ }^{11}$ Haro NE, Faloon WW. The effect of bicarbonate on pancreatic enzyme activity. (Abstract) Clin Res 1964; 12: 207.

${ }^{12}$ Leite CA, Kalser MH, Warren WD. Efficacy of pancreatic replacement therapy in patients with a $95 \%$ pancreatectomy and gut continuity. (Abstract) Gastroenterology 1967; 52: 1104.

${ }^{13}$ Veeger W, Abels J, Hellemans N, Niewig HO. Effect of sodium bicarbonate and pancreatin on the absorption of vitamin $\mathbf{B}_{12}$ and fat in pancreatic insufficiency. $N$ Engl J Med 1962; 267: 1341-4.

${ }^{14}$ Weber A, Roy C, Chartrand L, Dufour O, LaSalle R. Influence of sodium bicarbonate supplement on faecal fat and bile acid secretion in cystic fibrosis. VII International Cystic Fibrosis Congress 1976, Paris.

${ }^{15}$ Holsclaw D, Fahl J, Keith H. Enhancement of enzyme replacement therapy in cystic fibrosis. Cystic Fibrosis Club Abstracts 1979, Atlanta, Georgia, USA.

${ }^{16}$ Weber A, DeGheldere B, Roy C, et al. Effectiveness of enteric coated pancrease in cystic fibrosis. Cystic Fibrosis Club Abstracts 1979, Atlanta, Georgia, USA.

${ }^{17}$ Bell L, Hatcher J, Chan L, Fraser D. Development of a computerized system for calculating nutrient intakes. J Can Diet Assoc 1979; 40: 30-6.

${ }^{18}$ Van der Kamer J. In: Seligson D, ed. Standard methods of clinical chemistry, vol 2. New York: Academic Press, 1958: 34 . 
${ }^{19}$ Horowitz W. ed. Official methods of analysis of the Association of Official Analytical Chemists. Washington, D.C.: Association of Official Agricultural Chemists, 1975.

${ }^{20}$ Bliss CI. Statistics in biology, vol 1. McGraw-Hill, 1967.

${ }^{21}$ SAS User's Guide. Raleigh, N.C.: SAS Institute Inc, 1979.

${ }^{22}$ Food Consumption Patterns Report. A report from I! Nutrition Canada by the Bureau of Nutritional Sciences Health Protection Branch, Dept of National Health and Welfare Publication, 1977, Ottawa: 50-70.

${ }^{23}$ Wollaeger EE, Comfort MW, Weir JF, Osterberg AE.

The total solids, fat and nitrogen in the feces I. A study of normal persons and of patients with duodenal ulcer on a test diet containing large amounts of fat. Gastroenterology 1946; 6: 83-92.

${ }^{24}$ Wollaeger EE, Comfort MW, Osterberg AE. Total solids, fat and nitrogen in the feces. III. A study of normal persons taking a test diet containing a moderate amount of fat; comparison with results obtained with normal persons taking a test diet containing a large amount of fat. Gastroenterology 1947; 9: 272-83.

${ }^{25}$ Young VR, Taylor YS, Rand WM, Scrimshaw NS. Protein requirements of man. $J$ Nutr 1973; 103: 1164-74.

${ }^{26}$ Cheng AHR, Gomez A, Bergan JG, Lee TC, Monckeberg $\mathrm{F}$, Chichester $\mathrm{CO}$. Comparative nitrogen balance study between young and aged adults using three levels of protein intake from a combination wheat-soy-milk mixture. Am J Clin Nutr 1978; 31: 12-22.

${ }^{27}$ Reifenstein EC Jr, Albright F, Wells SL. The accumulation, interpretation and presentation of data pertaining to metabolic balances. J Endocrinol 1945; 5: 367-95.

${ }^{28}$ Weber AM, Roy CC, Morin CL, LaSalle R. Malabsorption of bile acids in children with cystic fibrosis. $N$ Engl J Med 1973; 289: 1001-5.

${ }^{29}$ Roy CC, Weber AM, Morin CL, et al. Abnormal biliary lipid composition in cystic fibrosis. $N$ Engl J Med 1977; 297: 1301-5.

${ }^{30}$ Reemtsma K, Di Sant'Agnese P, Malm JR, Barker HG. Cystic fibrosis of the pancreas: Intestinal absorption of fat and fatty acid labelled with $\mathbf{I}^{131}$. Pediatrics 1958; 22: 525-32.

${ }^{31}$ Di Sant'Agnese PA, Talamo RC. Pathogenesis and physiopathology of cystic fibrosis of the pancreas. N Engl J Med 1967; 277: 1287-94.

${ }^{32}$ Lapey A, Kattwinkel J, Di Sant'Agnese P, Laster L. Steatorrhea and azotorrhea and their relation to growth and nutrition in adolescents and young adults with cystic fibrosis. J Pediatr 1974; 84: 328-34.

${ }^{33}$ Gibson JA, Sladen GE, Dawson AM. Protein absorption and ammonia production: The effects of dietary protein and removal of the colon. Br J Nutr 1976; 35: $61-5$. 